\title{
HEALTH ECONOMICS LETTERS \\ DECOMPOSITION OF HEALTH INEQUALITY BY DETERMINANTS AND DIMENSIONS
}

\author{
JØRGEN LAURIDSEN ${ }^{\mathrm{a}, *}$, TERKEL CHRISTIANSEN ${ }^{\mathrm{b}}$, JENS GUNDGAARD $^{\mathrm{b}}$, UNTO HÄKKINEN $^{\mathrm{c}}$ \\ and HARRI SINTONEN ${ }^{\mathrm{d}}$ \\ ${ }^{\mathrm{a}}$ Department of Business and Economics, University of Southern Denmark, Denmark \\ ${ }^{\mathrm{b}}$ Institute of Public Health - Health Economics, University of Southern Denmark, Denmark \\ ${ }^{\mathrm{c}}$ Centre for Health Economics at STAKES (CHESS), Helsinki, Finland \\ ${ }^{\mathrm{d}}$ Department of Public Health, University of Helsinki, Finland
}

\begin{abstract}
SUMMARY
The study integrates two methodologies so that income-related inequality in general health can be decomposed into contributions from socio-demographic characteristics to each of the dimensions defining general health. It is found that these relative contributions vary substantially across dimensions. For policy purposes such information is valuable as it indicates at which population groups and at which aspects of health efforts to reduce inequalities in health should be targeted. Copyright (C) 2006 John Wiley \& Sons, Ltd.
\end{abstract}

Received 11 March 2005; Accepted 4 May 2006

JEL classification: D30; D31; I10; I12.

KEY WORDS: inequality; health; 15D; decomposition; Finland

\section{INTRODUCTION}

The concentration index has become a standard tool for the measurement of income-related health inequality in a single health variable (see Sen, 1997 for an extensive review). While such analyses provide an overall measure of income-related inequality in health, it is often useful to analyse at a disaggregated level to understand the sources of inequality. This can be done in two complementary ways. First, inequality in health stems from inequality in the determinants of health as measured by socio-economic determinants, and it is thus relevant to decompose inequality in health into relative contributions from these determinants. Methodology for such analyses has been well established (Kakwani et al., 1997; van Doorslaer et al., 1997; van Doorslaer and Jones, 2003; Wagstaff et al., 2003; van Doorslaer and Koolman, 2004). Second, inequality in an overall measure of health such as the 15D is naturally ascribed to inequality emerging from each of its dimensions (Yao, 1999; Clarke et al., 2003). The purpose of the present study is to integrate these two approaches, so that the contribution from determinants to overall health inequality is decomposed into relative contributions via each dimension of health.

To our knowledge, only one similar study has been done earlier, but with a restricted methodological approach (Clarke et al., 2003). They decomposed the overall inequality of the physical functioning of

*Correspondence to: Department of Business and Economics, University of Southern Denmark, Campusvej 55, DK-5230 Odense M, Denmark. E-mail: jtl@sam.sdu.dk 
the SF-36 into inequality in each of the ten items along lines similar to those applied in the present paper. When decomposing the contribution of socio-demographic determinants into contributions to the inequality of each single component, the methods of Clarke et al. (2003) were restricted to one-way ANOVA, whereby contributions of population subgroups (divided according to values of a one-dimensional socio-demographic determinant) were analysed. They analysed the impact of employment status, specified as employed versus non-employed (i.e. 2 groups) and the impact of income, specified as income deciles (i.e. 10 groups). This approach has two major limitations. First, the effect of one socio-demographic determinant is not adjusted for the effects of other determinants; in this case the effect of employment status is not adjusted for income effect. Thus, due to the obvious correlation between employment status and income, the effects of these derived from one-way ANOVA may provide biased conclusions. This shortcoming may be remedied by using $K$-way ANOVA comprised of $K$ classifying determinants with interaction. However, such a procedure may easily fail due to the strong imbalance of the $K$-way classification; for example, one may hardly expect to find unemployed in the high-income deciles. A further shortcoming of the $K$-way ANOVA is its inapplicability to continuous determinants. Both shortcomings are avoided by using the multivariate regression approach that is proposed in the present study. A further advantage of the regression approach is that it facilitates a decomposition of the impact of each single determinant on inequality in a health dimension into (i) its regressive impact on variation in the health dimension, and (ii) the impact due to income-related inequality in the determinant itself (Wagstaff et al., 2003).

\section{THE 15D INSTRUMENT}

The basic idea behind the development of the 15D was to develop a generic, multidimensional, standardised, self-administered measure of health-related quality of life, which could be used primarily as a single index measure, but also as a profile measure (Sintonen, 1994, 1995, 2001). The present 15D questionnaire includes the following 15 dimensions: breathing, mental function, speech (communication), vision, mobility, usual activities, vitality, hearing, eating, elimination (i.e. bladder and/or bowel function), sleeping, distress, discomfort and symptoms, sexual activity, and depression.

The valuation system of the $15 \mathrm{D}$ is based on an application of multi-attribute utility theory. A set of utility or preference weights, elicited from the general public through a valuation procedure is used in an additive aggregation formula to generate the $15 \mathrm{D}$ score as a weighted sum of its 15 dimensions (Sintonen, 2001). The 15D was developed to meet a number of requirements set for a useful generic measure (Torrance et al., 1982; Boyle and Torrance, 1984; Kirshner and Guyatt, 1985; Guyatt et al., 1989). A number of studies provide evidence that the 15D index meets these requirements; see the summary in Sintonen (2001). Thus, it is to be expected that conclusions based on investigating the 15D index should be general and hold true for other index measures, which meet the above requirements.

\section{METHODS}

As the $15 \mathrm{D}$ score is composed as a weighted sum of 15 dimensions, its concentration index can be decomposed into 15 components along the lines suggested by Yao (1999). Further, the concentration indices of the 15D and the dimensions can be obtained by regressions on fractional income ranks along the lines of Kakwani et al. (1997) and van Doorslaer et al. (1997). To quantify the importance of determinants, the decomposition of each concentration index into contributions from determinants established by Wagstaff et al. (2003) is applied. Combining these, a full decomposition of the overall 
inequality is obtained as (Lauridsen et al., 2006)

$$
\begin{aligned}
C_{15 \mathrm{D}} & =\Sigma_{j, k}\left(\mu_{k} / \mu\right) \delta_{j k} C_{k}+\Sigma_{j}(1 / \mu) \mathrm{CG}_{j} \\
& =C_{\text {PRED }}+\mathrm{CG}_{15 \mathrm{D}}
\end{aligned}
$$

where $\mu$ and $\mu_{k}$ are averages of $15 \mathrm{D}$ and the $k$ th determinant, $\delta_{j k}$ the regression coefficient of dimension $j$ on determinant $k, C_{15 \mathrm{D}}, C_{\mathrm{PRED}}$ and $C_{k}$ the concentration indices of observed and predicted $15 \mathrm{D}$ and the $k$ th determinant, and $\mathrm{CG}_{15 \mathrm{D}}$ and $\mathrm{CG}_{j}$ the residual unexplained inequality of $15 \mathrm{D}$ and dimension $j$.

The strategy of the study is to apply decomposition (1), in order to quantify the relative contribution of each determinant to each dimension. By evaluating the sum over $k$, the contribution from dimension $j$ is quantified, while the contribution from the $k$ th determinant is obtained by evaluating the sum over $j$. Finally, the overall predicted inequality of $15 \mathrm{D}$ is obtained by evaluating both sums.

\section{DATA}

The data are based on the Finnish Health Care Survey in 1995/1996, which is a national representative cross-sectional sample of the total non-institutionalised population (Arinen et al., 1998). The present study applies a subset of 3695 cases (aged 15-92) for which the 15D data were available. The overall response rate was $87.2 \%$. The $15 \mathrm{D}$ score was obtained by using the importance weights and level values from a representative sample of the Finnish population (Sintonen, 1994, 1995, 2001).

Following recent practice (van Doorslaer and Koolman, 2004), determinants of the regressions are the respondent's income (log of net household income in Finnish Mark, adjusted for household composition, using the approach suggested by Aronson et al. (1994), with both parameters set equal to 0.5 ), age, gender, activity status, educational level, and marital status. Interaction effects between age and gender and non-linearity in the age effect are captured by specifying age categories for each gender.

\section{RESULTS}

Descriptive statistics and concentration indices for the 15D score, its dimensions and the sociodemographic characteristics are provided in Lauridsen et al. (2006), together with OLS regressions of the $15 \mathrm{D}$ score and each of its dimensions on the determinants. While these regressions were based on a cross-section and are thus unable to address problems related to endogeneity between health and determinants as well as presence of structural common factors, strong effects of determinants were clearly demonstrated.

Table I reports the contributions of each determinant to income-related inequality on each of the 15 dimensions as percentage of the overall predicted concentration index for 15D. For each dimension the predicted inequality component can be calculated as the simple sum of the contributions of each determinant to it. These figures are found in the last row of the table. The last column reports the sum of the contributions of each determinant to the 15 dimensions, thus representing the contribution of the determinants to the deterministic part of the overall inequality via deterministic contribution to the dimensions.

Looking at the direct effects of the determinants, the column for $C_{\mathrm{PRED}}$ shows that the strongest contributors are retired, income and females older than 70. Of particular policy relevance is that low income has a substantial effect. Further, looking at the contributions from health dimension, the largest contributions to health inequality come from sexual activity, usual activities, mental function, breathing and mobility. Thus, public health initiatives aiming at reducing health inequality should be expected to have larger effects if targeted at retired people - especially females older than 70 - and at low income groups. Considering health dimensions, the large inequality in sexual problems is striking and is an 


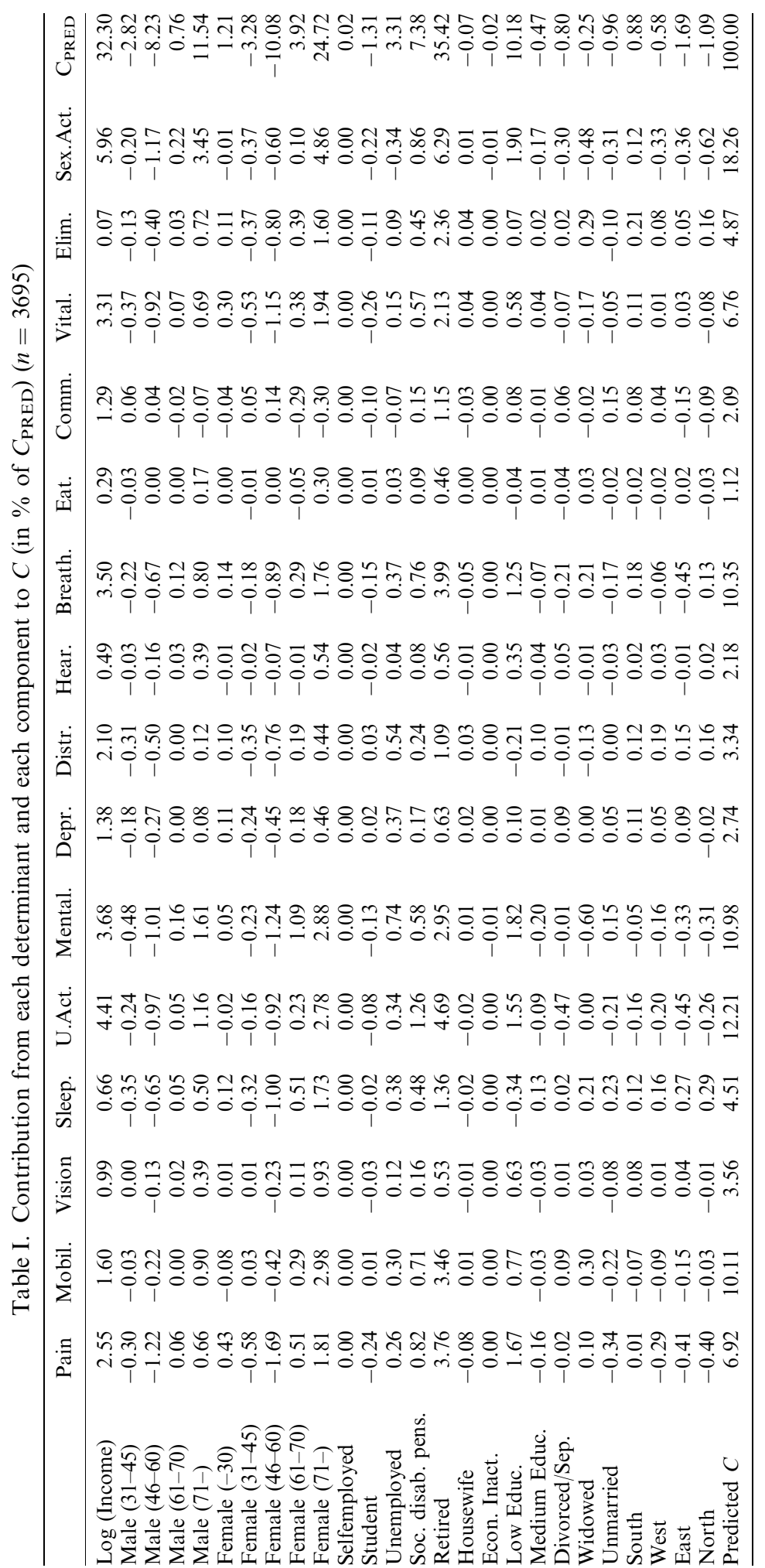


evident target for initiatives, together with problems related to usual activities, mobility and breathing problems. Considering the detailed contributions from each determinant to the dimensions, further targets for public initiatives may be obtained. Thus, for the case of retired people, larger effects should be expected if policies are directed toward mobility, usual activities, mental function, discomfort and symptoms, breathing and sexual activity rather than if directed toward vision, depression, hearing and eating. Considering females older than 70, especial attention should be devoted to mobility, usual activities, mental function and sexual activity. Regarding low income people, special effort should be directed toward problems related to usual activities, sexual activities, mental function, vitality and breathing.

\section{CONCLUSION}

Health is a diversified matter and the overall index of health may be too crude a measure to look at alone. Potential gains of considering the varying importance of different dimensions of health when analysing income-related inequality in health are demonstrated. Further, it appears that the effects of socio-demographic determinants on different dimensions of health vary considerably. It is thus indicated that public health and social policy initiatives and programmes, aiming at reducing incomerelated inequality in health, should be targeted at specific dimensions of health and at specific population groups rather than being uniformly directed toward general health and the general population. As the study is based on cross-sectional data, the effects of determinants cannot be interpreted as causal effects. But it stands clearly out that major population subgroups, to which health inequality is connected, are retired people - especially females older than 70 - and people with low income. Finally, it appears clearly that some dimensions contribute heavier to health inequality than other. Such dimensions are especially sexual activity, usual activities, mental function, breathing and mobility.

\section{REFERENCES}

Arinen S, Häkkinen U, Klaukka T, Klavus J, Lehtonen R, Aro S. 1998. Suomalaisten terveys ja terveyspalvelujen käyttö. Terveydenhuollon väestötutkimuksen 1995/96 päätulokset ja muutokset vuodesta 1987 (Health and Use of Health Services in Finland. Main Findings of the Health Care Survey 1995/96 and Changes from 1987). Gummeruksen Kirjapaino, Helsinki, 1998.

Aronson J, Johnson P, Lambert P. 1994. Redistributive effect and unequal tax treatment. Economic Journal 104: 262-270.

Boyle M, Torrance G. 1984. Developing multiattribute health indices. Medical Care 22: 1045-1057.

Clarke P, Gerdtham U-G, Conelly L. 2003. A note on the decomposition of the health concentration index. Health Economics 12: 511-516.

Guyatt G, Deyo R, Charlson M, Levine M, Mitchell A. 1989. Responsiveness and validity in health status measurement: a clarification. Journal of Clinical Epidemiology 42: 403-408.

Kakwani NC, Wagstaff A, van Doorslaer E. 1997. Socio-economic inequalities in health: measurement, computation and statistical inference. Journal of Econometrics 77: 87-104.

Kirshner B, Guyatt G. 1985. A methodological framework for assessing health indices. Journal of Chronic Diseases 38: 27-36.

Lauridsen J, Christiansen T, Gundgaard J, Häkkinen U, Sintonen H. 2006. Decomposition of socio-economic determination of income-related health inequality by health dimensions. Working paper, Department of Business and Economics, Odense. http://www.sam.sdu.dk/economics/edp.html

Sen A. 1997. On Economic Inequality: Expanded Edition with a Substantial Annexe by James Foster and Amartya Sen. Clarendon Press: Oxford.

Sintonen H. 1994. The 15D measure of health related quality of life: reliability, validity and sensitivity of its health state descriptive system. Working Paper 41, National Centre for Health Program Evaluation, Melbourne (http:// www.buseco.monash.edu.au/centres/che/publications.php\#4). 
Sintonen H. 1995. The 15D measure of health related quality of life. II Feasibility, reliability and validity of its valuation system. Working Paper 42, National Centre for Health Program evaluation, Melbourne (http:// www.buseco.monash.edu.au/centres/che/publications.php\#4).

Sintonen H. 2001. The 15D instrument of health-related quality of life: properties and applications. Annales de Medicine 33: 328-336.

Torrance G, Boyle M, Horwood S. 1982. Application of multi-attribute utility theory to measure social preference for health states. Operations Research 30: 1043-1069.

van Doorslaer E, Jones A. 2003. Inequalities in self-reported health: validation of a new approach to measurement. Journal of Health Economics 22: 61-87.

van Doorslaer E, Koolman X. 2004. Explaining the differences in income-related health inequalities across European countries. Health Economics 13: 609-628.

van Doorslaer E, Wagstaff A, Bleichrodt H et al. 1997. Income-related inequalities in health. Some international comparisons. Journal of Health Economics 16: 93-112.

Wagstaff A, van Doorslaer E, Watanabe N. 2003. On decomposing the causes of health sector inequalities with an application to malnutrition inequalities in Vietnam. Journal of Econometrics 112: 207-223.

Yao S. 1999. On the decomposition of the Gini coefficients by population class and income source: a spreadsheet approach and application. Applied Economics 31: 1249-1264. 